\title{
Adaptive Significance of Female Physical Attractiveness: Role of Waist-to-Hip Ratio
}

\author{
Devendra Singh
}

\begin{abstract}
Evidence is presented showing that body fat distribution as measured by waist-to-hip ratio(WHR) is correlated with youthfulness, reproductive endocrinologic status, and long-term health risk in women. Three studies show that men judge women with low.WHR as attractive. Study 1 documents that minor changes in WHRs of Miss America winners and Playboy playmates have occurred over the past 30-60 years. Study 2 shows that college-age men find female figures with low WHR more attractive, healthier, and of greater reproductive value than figures with a higher WHR. In Study 3 , 25- to 85-year-old men were found to prefer female figures with lower WHR and assign them higher ratings of attractiveness and reproductive potential. It is suggested that WHR represents an important bodily feature associated with physical attractiveness as well as with health and reproductive potential. A hypothesis is proposed to explain how WHR influences female attractiveness and its role in mate selection.
\end{abstract}

Evolutionary theories of human mate selection contend that both men and women select mating partners who enable them to enhance reproductive success. Differential reproductive conditions and physiological constraints in men and women, however, induce different gender-specific sexual and reproductive strategies. In general, a woman can increase her reproductive success by choosing a high-status man who controls resources and, hence, can provide material security to successfully raise her offspring. A man, on the other hand, can increase his reproductive success by choosing a woman who is receptive, highly fecund, and has characteristics suggestive of being a successful mother. The reproductive value of a man, as a rule, can be easily assessed because high status is usually achieved through competition with other members of the social and economic hierarchy. The reproductive value of a woman, however, cannot be as readily and accurately assessed because it is concealed. In the absence of any direct signals of ovulation or fertility, the man is forced to use indirect cues such as physical attractiveness to assess the reproductive value of the woman. It is the fundamental assumption of all evolution-based theories of human mate selection that physical attractiveness is largely a reflection of reliable cues to a woman's reproductive success (Buss, 1987; Kenrick, 1989; Symons, 1979). Consistent with this assumption is that men assign much greater significance to "good looks" (Buss, 1987; Feingold, 1990; Townsend, 1989), and this appears to be a cross-cultural universal (Buss, 1989).

I am grateful to Niels Dyrved, Debbie Lin, Jessica Lee, Rene Ton, Noelle Gracy, Christine Lawrence, and Stephanie Blackwood for help in collecting and organizing the data. I am also indebted to William Koch for multidimensional scaling analysis and to Lee Willerman, Arnold Buss, Michael Lilliquist, David Buss, and Delbert Thiessen for their helpful comments on drafts of this article. Finally, I acknowledge extremely helpful review comments by Paul Rozin.

Correspondence concerning this article should be addressed to Devendra Singh, Department of Psychology, University of Texas, Austin, Texas 78712
To evaluate the validity of the evolutionary explanation for mate selection, it is essential to define what constitutes good looks or attractiveness and to demonstrate that bodily features that signal attractiveness also provide clues about the proximate mechanisms regulating female reproductive potential and success.

So far, the research to identify bodily features that convey attractiveness has been sporadic, primarily because of the almost universal belief that attractiveness not only varies greatly among societies but also that it varies over time within a given society. Darwin (1871), on the basis of then available cross-cultural information, concluded that there is no universal standard of beauty with respect to the human body. Ever since, researchers have emphasized cultural differences in definitions of attractiveness, although most of the quoted cross-cultural data are not based on standardized data-gathering procedures, and at times descriptive data are anecdotal and seem to be compiled for their amusement value. For example, Darwin quoting Hearne, "an excellent observer who lived many years with American Indians," described the beauty ideal of a Northern American Indian as "broad at face, small eyes, huge cheekbones, three or four broad black lines across each cheek, a low forehead, a large broad chin, a clumsy hook nose, a tawny hide and breast hanging down to the belt" $(1871, \mathrm{p}$. 590). The data contained in the Human Relations Area files on preliterate societies have been frequently used to compare beauty preference among various societies (cf. Ford \& Beach, 1951) yet suffers from similar problems.

Evidence for secular changes in the definition of attractiveness in Western society (no studies apparently have been conducted to investigate changes in the ideal of beauty over time within a given preliterate society) have been inferential and based on select samples, such as fashion magazine models, Playboy centerfolds, and Miss America contestants. Many references have been made to nude paintings by famous artists (Titian and Rubens, for example), and these paintings are compared with present-day fashion models to underscore changing 
ideals of attractiveness in the West (Garner, Garfinkel, Schwartz, \& Thompson, 1980; Mazur, 1986; Silverstein, Perdue, Peterson, \& Kelly, 1986).

This belief of vast variability within and among cultures has hampered any systematic search to determine whether there are cross-cultural commonalities in female physical attractiveness. Ethnic groups differ from each other on many morphological features such as color of the skin and hair, shape of nose, eyes, lips, as well as culturally determined, acquired features, such as hairstyle, alteration of face, depressed and elongated forehead, bound feet, and embossed skin. These culturally determined features play an important role in group-membership identification and status within a given society, although to a nonmember such features may be quite unappealing or even repulsive. If evolutionarily based explanations for mate selection are valid, culturally conditioned features by themselves should not signal the reproductive potential of the female. In other words, such features should be important in final mate selection only when some other morphological features that are related to a female's reproductive potential and success are already present and detectable to the male.

Thus, to demonstrate that female physical attractiveness has any adaptive significance, it is essential to identify those bodily features that not only signal attractiveness but also have at least plausible linkage to physiological mechanisms regulating some component of fitness such as health, fecundity, and capacity to sustain pregnancy and nurse a child. In addition, it should be possible to show that (a) variation in bodily features constituting attractiveness are correlated with variation in reproductive potential and success, and (b) males possess mechanisms to detect such features and that these features are assigned greater importance over other features in assessing female attractiveness. On the basis of presently available experimental evidence, the body fat and its distribution meet most of the above stated criteria.

\section{Gender Differences in Body Fat Distribution}

The fat distribution in humans depends both on their age and their sex; the sexes are similar in infancy, early childhood, and old age, and differences in fat distribution are greatest from early teenage until late middle age (Vague, 1956). Furthermore, the fat distribution in humans is regulated by steroid hormones, and fat can be used from one region of the body at the same time as it is being accumulated at another (Pond, 1981).

Extensive studies by Björntorp $(1987,1988,1991$ a) and by Rebuffé-Scrive (1987a, 1987b, 1988, 1991) have demonstrated the ways sex hormones affect specific regional adiposity and regulate utilization and accumulation of fat. The most striking gender-specific difference in the physiology of fat accumulation and utilization are observed in the abdominal and gluteofemoral (buttocks and thighs) regions. Simply stated, testosterone stimulates fat deposits in the abdominal region and inhibits fat deposits in the gluteofemoral region. The estrogen, in contrast, inhibit fat deposits in the abdominal region and maximally stimulate fat deposits in the gluteofemoral region more than in any other region of the body. These differential effects of sex hormones on regional fat accumulation and utilization (testosterone stimulates fat utilization in the gluteofemoral re- gion, whereas estrogen increases fat utilization in the abdominal region) produce a gynoid or an android body fat distribution (for review, see Björntorp, 199 1a).

The gynoid and android fat distribution can be ascertained by measuring waist (narrowest portion between ribs and the iliac crest) and hip (at the level of the greatest protrusion of the buttocks) circumferences and computing a waist-to-hip ratio (WHR). WHR reflects both the distribution of fat between upper and lower body and relative amount of intra- versus extraabdominal fat. WHR is a stable measure with high withinperson reliability and is significantly correlated $(r=.61)$ with direct measures of the intraabdominal-subcutaneous fat ratio (Ashwell, Cole, \& Dixon, 1985) as well as with deep abdominal fat $(r=.76)$ (Després, Prudhomme, Pouliot, Tremblay, \& Bouchard, 1991), using computed tomography scanning.

Before puberty, both sexes have similar WHRs. However, after puberty, females deposit more fat on the hips and, therefore, WHR becomes significantly lower in females than in males. WHR has a bimodal distribution with relatively little overlap between genders (Marti et al., 1991). The typical range of WHR for healthy premenopausal women has been shown to be .67-.80 (Lanska, Lanska, Hartz, \& Rimm, 1985; Marti et al., 1991 ; O'Brien \& Shelton, 1941), whereas healthy men have WHRs in the range of .85-.95 (Jones, Hunt, Brown, \& Norgan, 1986; Marti et al., 1991). Women typically maintain a lower WHR than men except during menopause when female WHR becomes similar to that of male WHR (Kirschner \& Samojilik, 1991).

\section{WHR, Reproductive Function, and Health Status}

There is growing evidence indicating that WHR is an accurate somatic indicator of reproductive endocrinologic status and long-term health risk (Table 1).

The relationship between WHR and reproductive potential can be inferred from the findings that body-weight-matched girls with relatively lower WHR exhibit earlier pubertal endocrine activity, as measured by high levels of lutenizing hormone and follicle-stimulating hormone as well as sex steroid activity (estradiol; DeRidder et al., 1990). A direct relationship between WHR and fertility has been reported recently; married women with higher WHR and lower body mass index (BMI) report having more difficulty becoming pregnant and have their first live birth at a later age than married women with lower WHR (Kaye, Folsom, Prineas, Potter, \& Gapstur, 1990).

It seems that the level of circulating estrogen (indicative of the degree of estrogenicity) when high, lowers WHR, whereas levels of circulating testosterone (degree of androgenicity) increase WHR. For example, nonobese women of reproductive age who suffer from polycystic ovarian syndrome and have an elevated testosterone level, have malelike higher WHR (Rebuffe-Scrive, Cullberg, Lundberg, Lindstedt, \& Björntorp, 1989). In nonobese postmenopausal women, WHR is relatively lower in those who use estrogen-enhancing medication (Tonkelaar, Seidell, van Noord, Baander-van Halewijn, \& Ouwehand, 1990). Similarly, men suffering from hypogonadism, Klinefelter syndrome, or advanced cirrhosis (conditions that are associated with reduced testosterone and elevated estrogen production) have the lower WHR typically observed in normal weight 
Table 1

Characteristics of Women With Upper and Lower Body Obesity

\begin{tabular}{|c|c|c|c|}
\hline Measure & $\begin{array}{l}\text { Upper } \\
\text { body } \\
\text { (android) } \\
\text { obesity }\end{array}$ & $\begin{array}{l}\text { Lower body } \\
\text { (gynoid) obesity }\end{array}$ & References \\
\hline Waist-to-hip ratio & $>.85$ & $<.85$ & Barbieri (1990) \\
\hline \multicolumn{4}{|l|}{ Reproductive capability } \\
\hline $\begin{array}{l}\text { Onset of pubertal endocrine } \\
\text { activity }\end{array}$ & Late & Early & DeRidder et al. (1990) \\
\hline $\begin{array}{l}\text { Level of percentage free } \\
\text { testosterone }\end{array}$ & High & Low & $\begin{array}{l}\text { Evans, Hoffman, Kalkoff, and } \\
\text { Kissebah (1983) }\end{array}$ \\
\hline \\
\hline globulin (SHBG) & Low & High & Evans et al. (1983) \\
\hline $\begin{array}{l}\text { Prevalence of } \\
\text { hyperandrogynism }\end{array}$ & High & Moderate to low & $\begin{array}{l}\text { Barbieri (1990); Evans et al. } \\
\quad(1983)\end{array}$ \\
\hline \multicolumn{4}{|l|}{ Health status } \\
\hline Plasma triglycerides & Elevated & Normal & $\begin{array}{l}\text { Barbieri (1990); Larsson } \\
\text { (1985) }\end{array}$ \\
\hline Severity of insulin resistance & $\begin{array}{l}\text { Moderate } \\
\text { to severe }\end{array}$ & Mild & $\begin{array}{l}\text { Barbieri (1990); Hartz, } \\
\text { Rupley, and Rimm (1984) }\end{array}$ \\
\hline $\begin{array}{l}\text { Risk for NIDDM (Type II } \\
\text { diabetes) }\end{array}$ & High & Moderate to low & $\begin{array}{l}\text { Barbieri (1990); Björntorp } \\
\text { (1988) }\end{array}$ \\
\hline Risk of gallbladder disease & High & Moderate to low & Hartz et al. (1984) \\
\hline $\begin{array}{l}\text { Risk for carcinomas } \\
\text { (endometrial, ovarian, } \\
\text { and breast) }\end{array}$ & High & Moderate to low & $\begin{array}{l}\text { Lapidus, Helgesson, Merck, \& } \\
\text { Bjorntorp (1988); Schapira } \\
\text { et al. (1991) }\end{array}$ \\
\hline $\begin{array}{l}\text { Risk for hypertension, heart } \\
\text { disease, stroke, and } \\
\text { mortality }\end{array}$ & High & Moderate to low & $\begin{array}{l}\text { Björntorp (1988); Larsson } \\
\text { (1985); Raison and Guy- } \\
\text { Grand (1985) }\end{array}$ \\
\hline
\end{tabular}

Note. NIDDM = non-insulin dependent diabetes mellitus.

women (Kirschner \& Samojilik, 1991). Men treated with estrogen for cancer of the prostate develop gynoid fat distribution and lower WHR (Krotkiewski \& Björntorp, 1978).

Besides being a reliable signal of reproductive age and reproductive capability, low WHR also accurately signals health as defined by absence of major diseases. A large number of studies have found that the risk-factor profile for major obesity-related diseases such as diabetes, heart attack, and stroke varies with the distribution of fat rather than total amount of fat (Björntorp, 1988, 199 1b; Leibel, Edens, \& Fried, 1989). WHR, which measures body fat distribution, therefore turns out to be a more powerful predictor of various diseases and symptoms than most other anthropometric measures. Hamilton and Zuk (1982) have proposed that features signaling good health play a critical role in mate choice. Choosing mates that are relatively resistant to current diseases ensures that the mate will be able to provide high parental care as well as provide genetic resistance for diseases for offspring (for a critical review, see Møller, 1990).

In summary, WHR reliably signals female reproductive status (pre- or postpubertal and menopausal), reproductive capability, and, to a certain degree, health status, as inferred from risk for major diseases. If the attributes of good health and reproductive capability are critical in mate selection as posited by evolutionarily based theories, then men should possess mechanisms (conscious or unconscious) to detect these features in women and assign them greater importance than other bodily features in assessing female attractiveness.

The present studies explore the role played by WHR in female attractiveness and, furthermore, ascertain whether men perceive WHR to be correlated with some component of female fitness. The first study reported here examines the historical importance of WHR within changing ideals of feminine beauty in America. If WHR indeed represents an essential attribute of female attractiveness, then the attractiveness of low WHR should have remained more or less constant during the last several decades, unlike, say, body weight or breast size.

\section{Study 1}

Some research suggests that the Western ideal of female attractiveness has undergone a dramatic change within the past century. Most of these studies have typically used fashion models, Playboy centerfolds, Miss America contestants, and famous 
film actresses to infer this changing ideal (e.g., Garner et al., 1980; Mazur, 1986; Silverstein et al., 1986). On the basis of such studies, a trend for the present-day emphasis on thinness and a slender female body in the United States is inferred. Furthermore, it has been suggested that the ideal body form of women is evolving away from the hourglass shape and is becoming tubular (Garner et al., 1980). The present study examines the bodily features and WHR changes in the same groups, namely, Playboy centerfolds and Miss America contest winners, as used in previous studies to identify changing criteria for female attractiveness (Garner et al., 1980; Mazur, 1986).

The study reported by Garner et al. (1980) is the earliest and most frequently cited source for inferring a recent trend toward idealization of thinness. These authors examined body measurement of Playboy centerfolds from 1960 to 1978 and found evidence of "a gradual but definite evolution in ideal body shape for women over the past 20 years" (Garner et al., 1980, p. 189). However, the data presented by Mazur (1986) for Miss America contestants from 1940 to 1985 indicate that, in spite of change in height and weight over these years, the body shape of the contestants has retained an hourglass shape rather than becoming tubular. Specifically, Mazur reported that from 1940 to 1985 , hip size changed from 35 in. to 34.5 in., waist from 24.5 in. to $23.5 \mathrm{in}$., and breast from $34 \mathrm{in}$. to $35 \mathrm{in}$. Thus, the average body measurement of 1940 contestants was 34-24.5-35 (WHR $=.70)$ and in 1987 was 35-23.5-34.5 (WHR = .68).

Because neither Garner et al. (1980) nor Mazur (1986) reported the size of WHR for their sample, it is not possible to determine whether WHR has stayed rather stable in the typical feminine range (below .80) in the samples used in these two studies. Therefore, published data for various bodily measurements were obtained for Playboy centerfolds between 19551965 and 1976-1990; bodily measurements for centerfolds were not published between 1966-1975 and were not available for data analysis. Data for Miss America winners from 1923 to 1987 (because of a policy change, bodily measurements since 1987 are no longer reported) were obtained from Bivans (1991). To isolate the trend for slenderness, the measure employed by Garner et al. (1980) was used, namely, percentage of ideal body weight based on the Metropolitan Life Insurance Company Weight Table (1959). Percentage of ideal body weight and WHR were calculated for each subject in both groups. Figure 1 shows percentage of ideal body weight and WHR for both Playboy centerfolds and Miss America contest winners. Consistent with previous findings, there was a clear trend toward slenderness for both Playboy centerfolds and Miss America contest winners as indicated by decreasing percentage of ideal weight.

WHR for Playboy centerfolds increased slightly from .68 to .71 over the years examined, whereas Miss America contest winners had WHR decrease from .72 to .69 (Figure 1). Thus, WHR of both Miss America contest winners and Playboy centerfolds, in spite of reduction of body weight over years, remained within the .68 to .72 range. ${ }^{1}$ Breast and hip measurements were practically identical for both Playboy centerfolds and Miss America contest winners for all years examined. Waist sizes were never found to approach either hip or breast measurement in either group, as would be required to suggest tubularity.

It appears that the inference that the Western female shape is becoming tubular is based on slenderness and smaller upper torso (especially the bust) rather than the lower body torso. For example, A. Morris, Cooper, and Cooper (1989) concluded that British fashion models over the period of 1967-1987 exhibited "a trend toward a more "tubular or androgynous' body shape" (p. 593). However, when WHRs were computed from reported measurements for these models, they fell between .68 and .69 , implying lack of tubularity at least in the lower body segment. Furthermore, other data that show that tubular female figures are not perceived as attractive by either male or female subjects (Furnham, Hester, \& Weir, 1990). Specifically, Furnham, Hester, and Weir (1990) obtained attractiveness judgments for normal weight female figures with tubular or hourglass shapes and found that both male and female subjects rated figures with small waists and large hips as more attractive than tubular figures.

It seems that, in Western societies, a narrow waist set against full hips has been a consistent feature for female attractiveness, whereas other bodily features, such as bustline, overall body weight, or physique, have been assigned various degrees of importance over the years. The narrow waistline emerges as one of the most stable and enduring bodily features throughout changing ideals of female attractiveness, whereas ideals of attractive body weight have dramatically fluctuated over the years. For example, Mazur (1986) mentioned that in 19th century America the ideals of feminine beauty included female differences in physique and personality (one being slight and frail and the other heavy and robust); however, "both share the ubiquitous corseted waist line, down to an 18 circumference, if possible" (p. 284). The British model, Twiggy, who epitomized slenderness and flat chestedness of fashion models in the early 1960 s, had a bodily measurement of 31-24-33 (Wilson \& Nias, 1976), which would have given her a low female WHR (73). D. Morris (1985) stated that the earliest cosmetic surgery in England consisted of removing two lower ribs to enhance the narrowness of the waist. The popularity of the corset, in spite of internal injury it caused to women, and fashionable clothing that stressed tiny waists and exaggerated hips are testimonials for the relationship of waist to hip as an erotic symbol. It should be noted that the technique for narrowing the waist with the help of a corset was abandoned in the 1950 s but was replaced by girdle, and in 1991, wide belts were being used by all leading fashion designers to stress the waist (Posnick, 1991).

Obviously, clothing and fashion can be used to make a political or personal statement (e.g., flapper style and punk), but very rarely are such trends adopted by most of society. Clothes can be worn for comfort (loose overall and tent dress), rather than for attracting attention, or to specifically deemphasize the body form (e.g., nun's habit and the chaddor to hide the female body in Iran and some Arab countries). It appears, however, that when the objective is to make a woman attractive, the most durable and persistent method has been to emphasize the narrow waist, as is historically evident in early Greek paintings and presently evident in Western female fashion using corset, bustle, and other devices (Rudofsky, 1974; Shorter, 1982).

\footnotetext{
${ }^{1}$ No inferential statistics for differences for body weight and WHRs were computed because the data analysis comprised the entire populations rather than samples.
} 

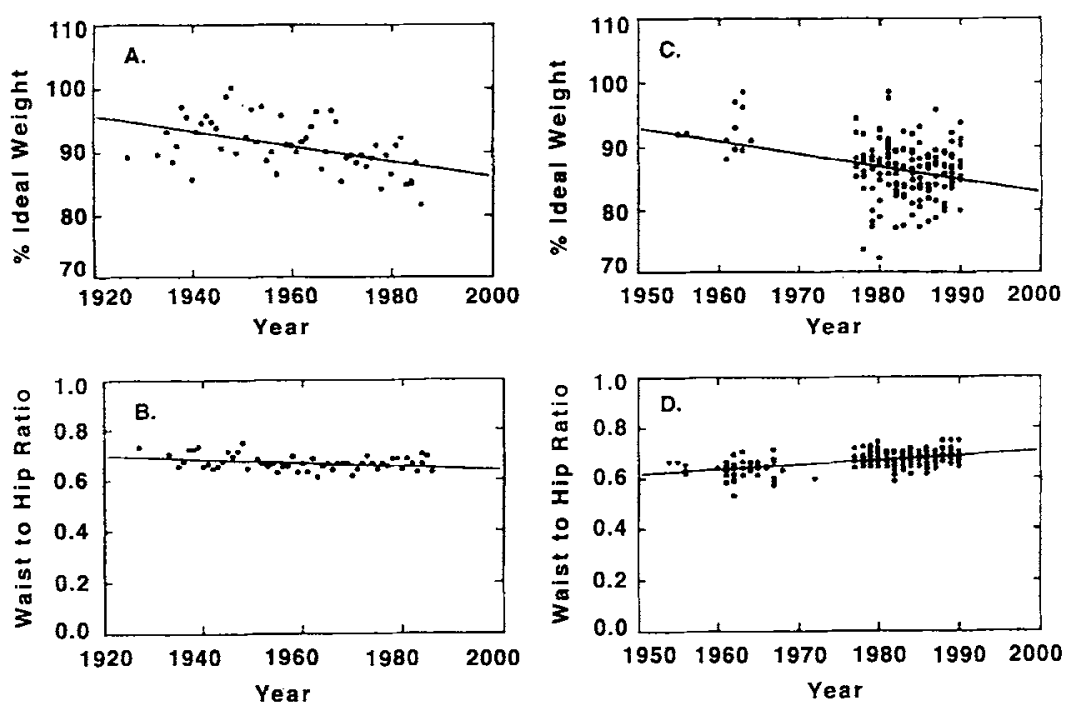

Figure 1. Comparison of Miss America winners' percentage ideal weight (A) and waist-to-hip ratios (WHRs) (B) with Playboy centerfold models' percentage ideal weight (C) and WHRs (D) over the years.

\section{Study 2}

The demonstration that Playboy centerfold models and Miss America winners have maintained a low WHR over the years proves neither that men find this feature attractive nor that it is a critical feature for defining female attractiveness. Obviously, many bodily features contribute in varying degrees to attractiveness, and it could be that in spite of its relationship to health and hormonal profile, WHR is not an important feature for assessing attractiveness. It is quite possible that other bodily features (such as the size and shape of breasts, legs, etc.) that may not signal a woman's health and hormonal states, are, nevertheless, used by men in determining female attractiveness. To establish that WHR represents a critically important feature that men find attractive in women, it would be necessary to demonstrate that male ratings of female attractiveness are significantly correlated with WHR. If such a relationship exists, it should be possible to systematically change men's evaluation of female attractiveness by manipulating the size of WHR alone. Study 2 explored this possibility.

\section{Method}

Subjects. One hundred six men ( 72 White and 34 Hispanic), aged 18-22 years volunteered to participate in this study as part of an undergraduate course requirement.

Stimulus materials. Stimuli consisted of 12 line drawings of female figures representing four levels of WHR $(.7, .8, .9$, and 1.0) and three levels of body weight (normal, under-, and overweight)

All figures were drawn to represent a 5-in., 5-ft tall woman; figures were supposed to represent a normal weight $(120 \mathrm{lb})$ woman, a an underweight $(90 \mathrm{lb})$ woman, and an overweight $(150 \mathrm{lb})$ woman. Within each of these body weight categories, all facial and bodily features were held constant except for WHR sizes, which were created by varying the line drawing representing the waist (Figure 2).

To check the validity of body weight categories, undergraduate male students aged 18-22 years $(n=72)$ were asked to identify figures they considered normal, under-, or overweight. All subjects except 3 assigned the same figures to the three body-weight categories as desig- nated by the experimenter. Figures were randomized and assigned identifying letters. Two separate random sequences of figure orders were used. In one set, figure sequences were $\mathrm{U} 8, \mathrm{U} 7, \mathrm{O} 8$, and $\mathrm{N} 7 ; \mathrm{N} 10$, $\mathrm{O} 10,09$, and $\mathrm{N} 9$; and $\mathrm{U} 10, \mathrm{U} 9, \mathrm{O} 7$, and $\mathrm{N} 8$, whereas for the other set the sequences were $\mathrm{O} 7, \mathrm{U} 7, \mathrm{~N} 8$, and $\mathrm{N} 9 ; \mathrm{N} 10, \mathrm{O} 9, \mathrm{U} 9$, and $\mathrm{U} 8$; and $\mathrm{N} 7$, $\mathrm{U10}, \mathrm{Ol0}$, and $\mathrm{O} 8$. All figures, for both sets, were reproduced on an 8 $1 / 2$-in. $\times 11$-in. sheet of white paper, and thus the subject could simultaneously examine all 12 figures.

Procedure. Subjects were given a typed page explaining the purpose of the experiment (the cover story) and a page containing 12 figures from one of the two sets. Subjects were asked to indicate their age, height, body weight, religious and ethnic affiliation, and to rank figures for physical attractiveness and various physical attributes. The following cover story titled "Body Types and Personality" was used.

Many people believe that people with particular bodily features (e.g., red hair, beady eyes, etc.) behave in certain ways or exhibit specific behavioral characteristics. Recent research shows that some behavior styles and belief systems (personality) are indeed affected by a person's shape and body build. Furthermore, and more intriguing, research shows that people can make amazingly accurate judgments about a person's personality by merely observing their full body photographs. The research in which you will be participating is intended to replicate and confirm research findings about body shape and personality. We are interested in finding out whether mere line drawings, as opposed to photographs, can be used to judge a person's personality. Please take time to carefully observe each outline of the body shape. You will be asked to compare and rank these various shapes for some physical and psychological characteristics.

All subjects were required to first rank all 12 figures from 1 (most attractive) to 12 (least attractive), without permitting tied ranks. Then, subjects were required to indicate their top 3 (the most) and lowest 3 (the least) rankings for each of the following characteristics in order: good health, youthful looking, attractive, sexy, desire for children, and capability for having children. ${ }^{2}$ Subjects again were not allowed to give

\footnotetext{
${ }^{2}$ The ranking for top 3 (the most) and lowest 3 (the least), rather than 12 rankings for various attributes, were obtained because of the recom-
} 

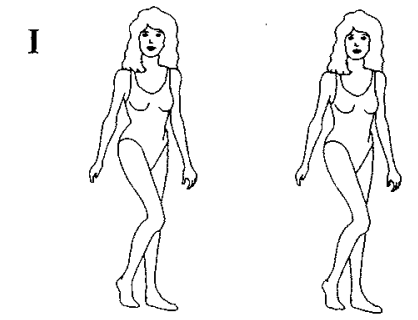

WHR $\quad 0.7(\mathbf{U} 7)$

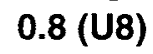

II

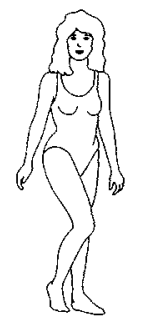

WHR
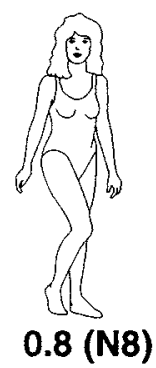

III

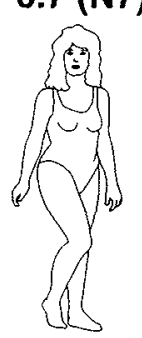

WHR
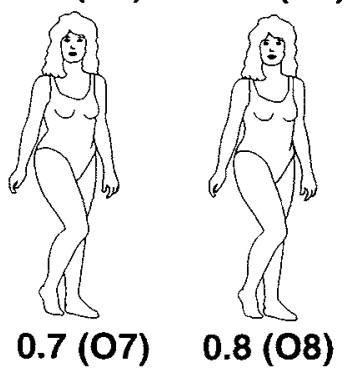

$0.8(08)$
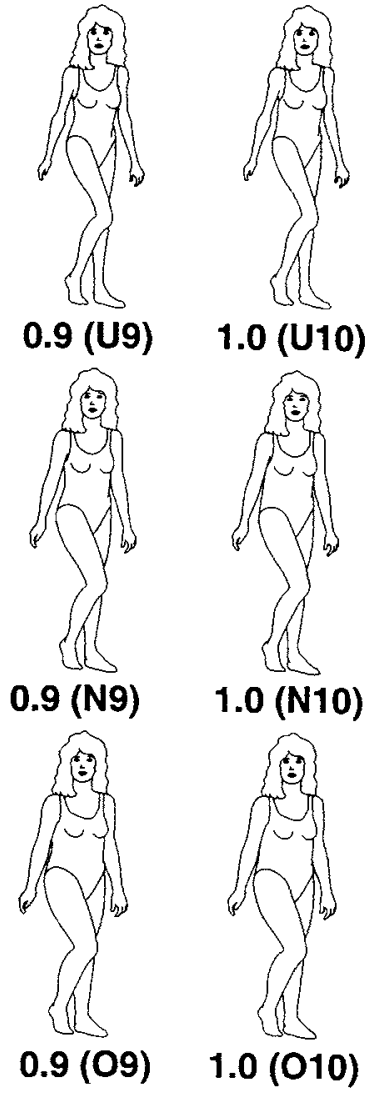

Figure 2. Stimulus figures representing three body weight categories: underweight (I), normal weight (II), and overweight (III). (Waist-tohip ratios [WHRs] shown under each figure in each weight category, along with a letter and a number in parentheses identifying body weight category WHR).

tied rankings. Subjects were instructed to make an educated guess if they found it difficult to assign a ranking for any attribute, but they had to assign all rankings for each attribute. At the end of the session, subjects were given a written debriefing.

\section{Results}

Attractiveness ratings by White and Hispanic subjects were compared for both forms (Sets 1 and 2) separately. The ratings of most and least attractive were similar for all subjects within each set; therefore, ethnicity and position (Set 1 vs. Set 2) vari-

mendation of Schiffman, Reynolds, and Young (1981). These researchers recommended ranking only a subset of stimuli when there are a large number. For example, they stated that it would be advantageous to rank order the 5 stimuli most like the standard and the 5 stimuli least like the standard, leaving the remainder unranked (p. 23). A variation on this theme is known as ends-to-the-middle ranking in which stimuli are ranked from both extremes toward the middle. With a large number of stimuli (e.g., more than 7), rankings are difficult and may be unreliable because of problems in discriminating among the middle stimuli that are perceived as being very similar (Mehrens \& Lehman, 1978). In contrast, it is easy for subjects to distinguish reliably among the highest and the lowest ranks. ables were not further analyzed. Next, the BMI index (weight/ height ${ }^{2}$ ) was computed for each subject to determine whether the subject's own obesity influenced his attractiveness ratings. Subjects were divided into three groups on the basis of their BMI score, using national norms (Cronk \& Roache, 1982): overweight (85th percentile or above), normal weight (50th-75th percentile), and underweight (20th percentile or below). Data for subjects who could not be assigned to any of these groups were excluded. No systematic effect of subjects' BMI for ranking on any attribute was found

A nonmetric multidimensional scaling (MDS) analysis of physical attractiveness of the 12 figures was performed after transformation of the attractiveness rankings into dissimilarities data. MDS is a mathematical technique that indicates proximity (similarity or dissimilarity scores that are based on the square root of the sum of squared rank differences) in the data structure by arranging the stimuli in a spatial configuration (Davison, 1983; Kruskal \& Wish, 1978). A two-dimensional solution using alternating least square scaling (ALSCAL) in the statistical analysis system (SAS, 1985) provided an excellent fit to the data (stress $=.037$; squared reliability coefficient $=.993$ ) suggesting that the rankings could be explained on the basis of two dimensions. As is evident from Figure 3, subjects ranked figures on the horizontal dimension (Dimension 1) strictly on the basis of WHR within both the normal and the underweight categories; a similar order of ranking for the overweight category was evident for WHRs of .7 and .8, although figures with WHRs of .9 and 1.0 were assigned virtually identical lower rankings. Thus, the distinctions among the four levels of WHR were not as clear for the overweight category. It is difficult to ascertain what Dimension 2 represents; although if Dimension 2 were rotated counterclockwise about $20^{\circ}$, there is a perfect progression from the underweight to normal to overweight categories. This dimension represents body weight along with some unidentifiable cues that subjects have used in rank ordering figures.

To ascertain whether the dimension (1) reflects physical attractiveness on the basis of WHR, attractiveness ratings (which required subjects to indicate top and bottom three rankings) were analyzed. For each figure, the percentage of frequency of Ist rank (most attractive) as well as the percentage of frequency of 12 th rank (least attractive) were computed (Figure 4).

The ranking order of attractiveness shown in Figure 4 was identical to the order shown in Dimension 1 of Figure 3 (MDS data), confirming that this dimension represents physical attractiveness on the basis of WHR. In both underweight and normal weight categories, subjects strictly rank ordered figures for attractiveness as a function of WHR. Figures with the lowest WHR were rated as most attractive, and as WHR increased, the attractiveness rating decreased. None of the figures in the overweight category was ranked as attractive, although figures with lower WHR were ranked as more attractive than figures with higher WHR. Across body weight categories, Figure N7 was ranked as most attractive, followed by underweight Figure U7, although some subjects $(2 \%)$ also ranked this figure as least attractive. Figures in the normal body weight category were consistently assigned the most attractive rank and never assigned the rank of 12 (least attractive) except for Figure N10. As 


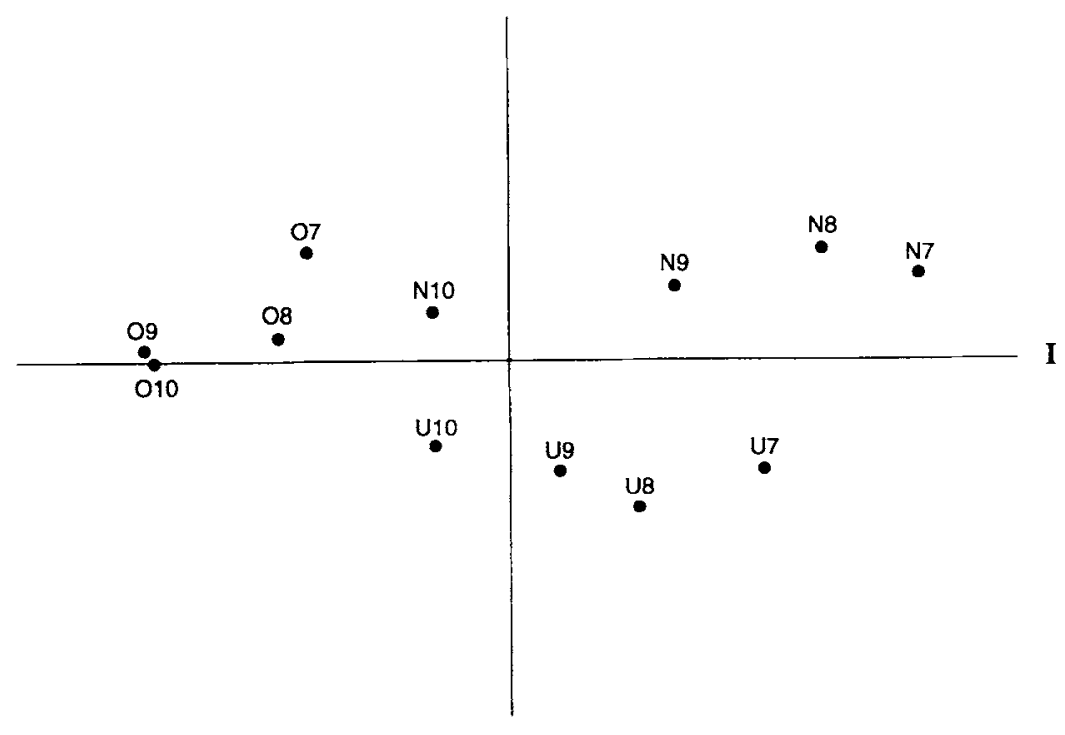

II

Figure 3. Multidimensional scaling for attractiveness rankings showing the proximities in stimulus figures on two dimensions. (I = waist-to-hip ratio; II = body weight. $)$

a group, the normal body weight figures accounted for $65 \%$ of rankings of most attractive, whereas underweight figures represented $35 \%$ of the most attractive ratings. This is quite a surprising finding given the generally present belief in American society that thin is beautiful and the fact that a very large number of girls and women are dieting in pursuit of thinness.
Ranking data on attributes of good health, youth, attractiveness, sexiness, and desire and capability for having children were subjected to multidimensional unfolding analysis. Multidimensional unfolding is a special type of nonmetric MDS in which two separate sets of stimuli (in this analysis, figures and attributes) may be scaled simultaneously into the same dimen-

Physical Attractiveness

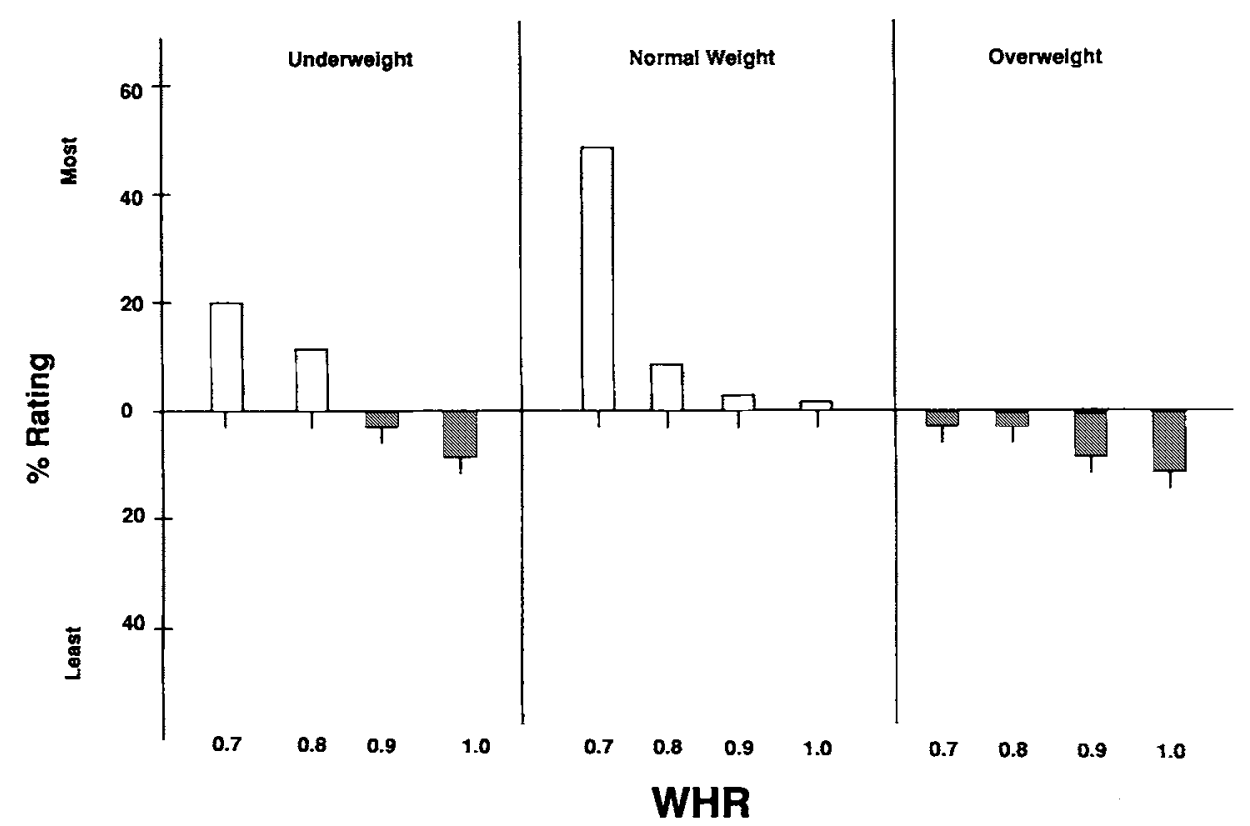

Figure 4. Percentage ranking for the most (average rank of 1) and the least (average rank of 12) physically attractive stimulus figures as a function of body weight category and waist-to-hip ratio (WHR). 


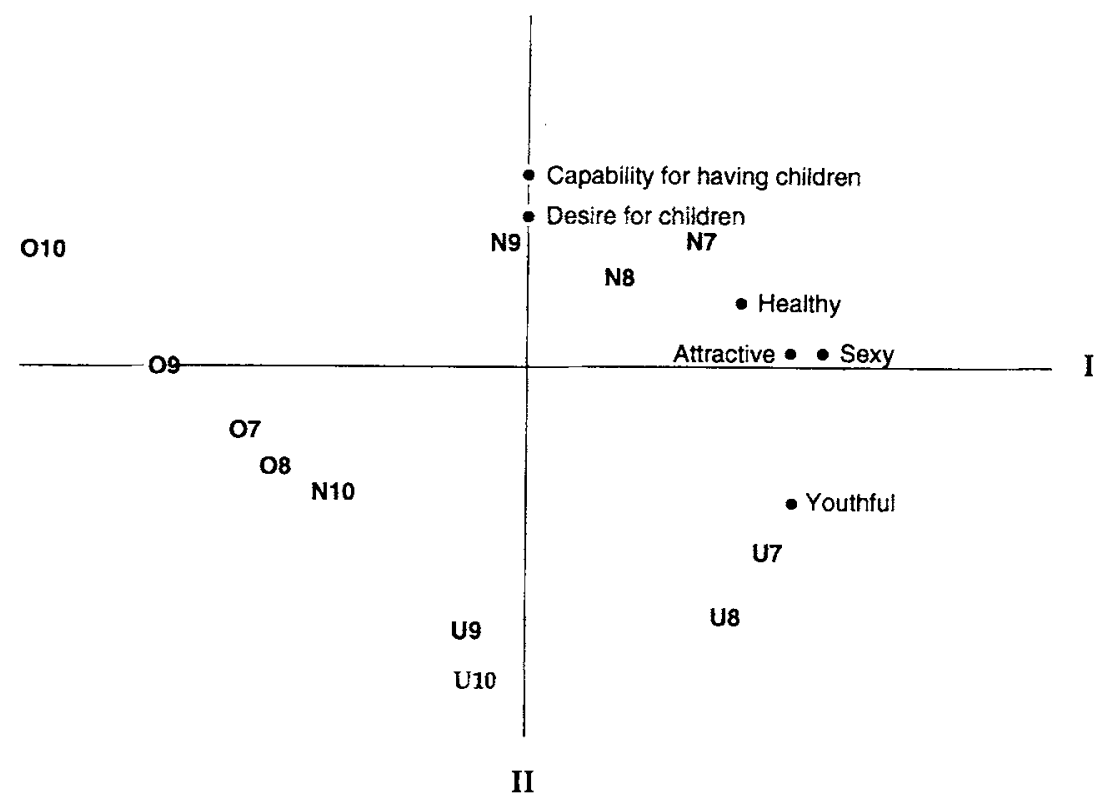

Figure 5. Multidimensional unfolding analysis showing the location of various attributes and stimulus figure. (Dimension I represents waist-to-hip ratio, and Dimension II represents body weight.)

sional solution space (Davison, 1983). In some ways, it provides information similar to cluster analysis (Davison \& Skay, 1991). Again two dimensions emerged for these figures and attributes (stress $=.023 ;$ squared multiple correlation coefficient $=.994$ ). The data, as shown in Figure 5, reveal three distinct regions for locations of the attributes. The variables of attractiveness, sexiness, and good health were located close to each other, suggesting that subjects perceived them to be closely related. Attributes of desire and capability for having children were located close to each other in the solution space but farther from attractiveness, sexiness, and good health, implying that subjects did not perceive a great similarity between these two sets of attributes. Finally, the attribute of youthfulness was located alone and away from both sets of other attributes. Thus, subjects apparently did not perceive youthfulness to be related to any other measured attributes of good health, sexiness, attractiveness, and desire and capability for having children.

Figure N7 was located closer to attractiveness, sexiness, and good health as well as desire and capability for having children than any other Figure. Figure N9 was located closest to desire and capability for having children, whereas Figure N8 was located between Figure N7 and Figure N9. The figure N10 was grouped along with overweight figures, which were not perceived to be closely associated with any of the attributes under investigation.

Underweight female figures, $\mathrm{U} 7$ and $\mathrm{U} 8$, were associated only with youthfulness. However, underweight figures with high WHR (U9 and U10) were perceived as neither youthful nor healthy, in spite of the fact that their depicted body weight was quite similar to figures with lower WHR. To ascertain whether WHR within each weight category systematically affected the ranking, the frequency for lst rank (most) and that of 12 th rank (least) were computed for each figure for each attrib- ute. The average ranking of 12 was subtracted from the average ranking of 1 to calculate the percentage of most and least ratings. The rankings for attractiveness and sexiness were pooled together because of virtually identical rankings for these two attributes. Another composite attribute that pooled the rankings of desire for children and capability for having children was created because of very similar rankings on these two attributes. Figure 6 depicts these data for attractiveness-sexiness, health, youthfulness, and desire and capability for having children as a function of body weight category and WHR.

Subjects systematically used WHR within each weight category for ranking all attributes. Figure N7 was ranked as being most attractive, most healthy, and most capable for having children. Figure U7 was assigned the highest ranking for youthfulness, second highest ranking for health and attractiveness, but low ranking for capability for having children. In both underweight and normal weight categories, figures with lower WHR were assigned higher ranking for all four attributes than were figures with higher WHR. Overweight figures were ranked as high for capability for having children if the figures had low WHR; however, low rankings were assigned to other attributes, although WHR clearly affected the rank orders for all four attributes.

To identify and interpret the meaning of Dimensions 1 and 2 , attributes were regressed to dimensions as recommended by Kruskal and Wish (1978). Specifically, each attribute was regressed on the set of coordinates that located the figure stimuli in the two-dimensional MDS solution space shown in Figure 3. Standardized regression coefficients for each attribute for these two dimensions are shown in Table 2 . It is obvious from the results presented in Table 2 that Dimension 1, based on WHR, had high regression coefficients with health, youth, sexiness, and attractiveness. 


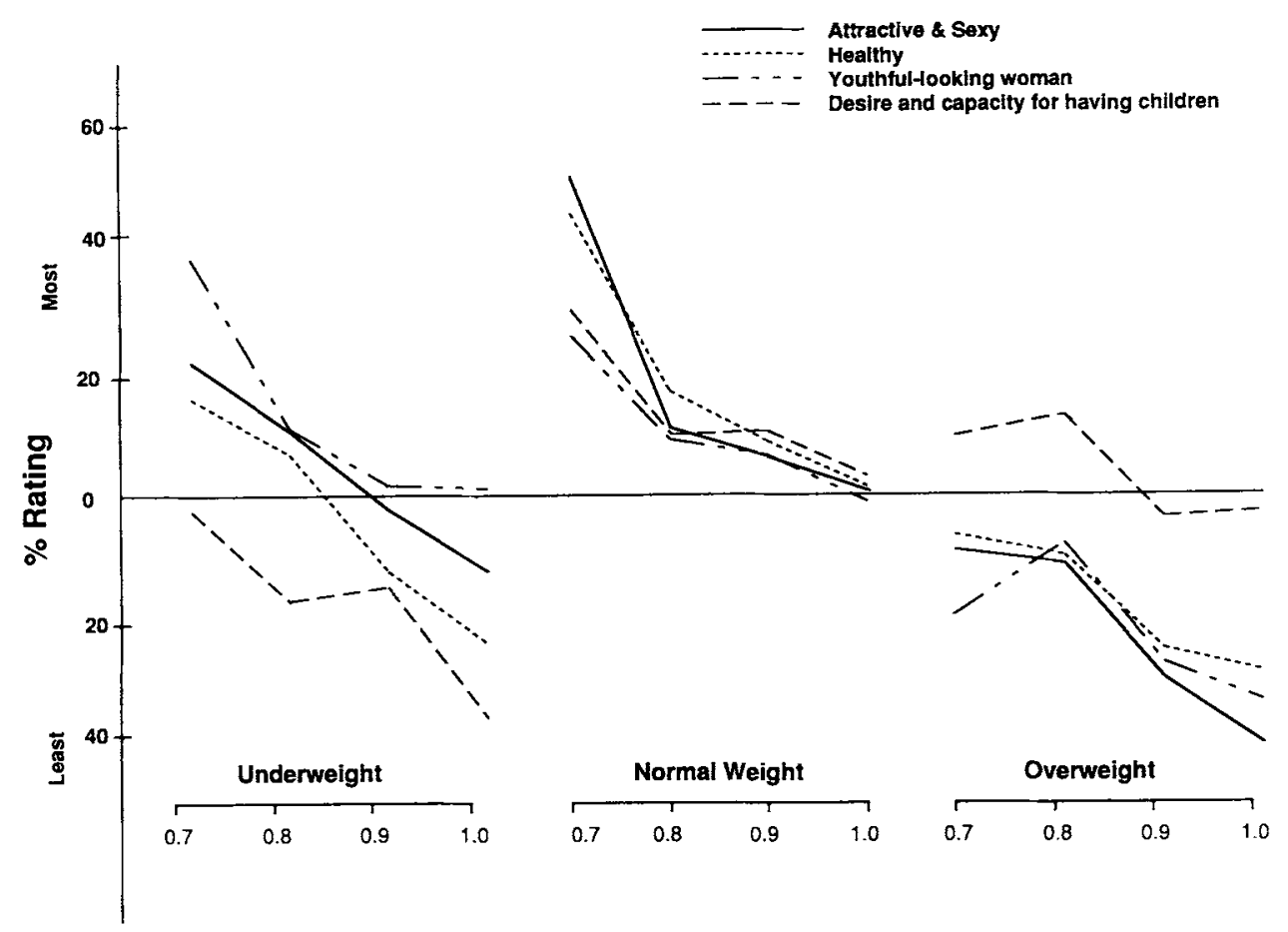

Figure 6. Average percentage composite ranking (average rank of 12 subtracted from average rank of 1 ) for attributes as a function of body weight category and waist-to-hip ratio.

Dimension 2, which predominantly represents body weight, had high regression coefficients with desire and capability for having children but not with other attributes. Overall, it seems that subjects inferred reproductive capability from body fat. Thus, it seems that although WHR is related to health and attractiveness, body weight is perceived to be related to reproductive capability. However, it should be pointed out that the relationship between reproductive capability and body weight was not linear. The highest reproductive capability was assigned to normal weight Figure N7 rather than overweight Figure O7; overweight Figures $\mathrm{O} 9$ and $\mathrm{O} 10$ were assigned lower reproductive capability than normal weight Figures N9 and N10 (Figure 6). As a group, underweight figures were assigned the lowest reproductive capability, followed by overweight figures and then normal weight figures.

Table 2

Standardized Regression Coefficients for

Dimensions 1 and 2 and Attributes

\begin{tabular}{lcc}
\hline & \multicolumn{2}{c}{ Regression coefficient } \\
\cline { 2 - 3 } \multicolumn{1}{c}{ Attribute } & Dimension 1 & Dimension 2 \\
\hline Healthy & .893 & .358 \\
Youthful & .939 & .284 \\
Attractive & .951 & .200 \\
Sexy & .936 & .229 \\
Desire for children & .065 & .899 \\
Capability for having children & .186 & .873 \\
\hline
\end{tabular}

\section{Discussion}

Overall, it appears that both fatness and thinness are perceived as unattractive, and such figures are not perceived as having especially high reproductive potential. The low attractiveness rating assigned to overweight figures is consistent with previous findings (Harris, Walters, \& Waschull, 1991). The low attractiveness for underweight figures, as a group, however, was quite unexpected. Besides the popular belief that thin is beautiful, studies by Fallon and Rozin (1985) and Rozin and Fallon (1988), using line drawings of female figures (figures in those studies differed on overall body weight but not on body fat distribution), also show that female college students consider thin women as representing ideal female figures. Interestingly enough, these authors found out that male students chose female figures that were slightly heavier than ideal figures chosen by female students as being more attractive. Thus, consistent with the present findings, men did not find thin or underweight figures attractive.

There is some evidence that suggests that being extremely underweight or overweight can have adverse effects on female reproductive functions. A critical body mass has been shown to be significantly related to the onset of menstrual cycle and its maintenance (Frisch \& McCarthur, 1974), although recent evidence (DeRidder et al., 1990) suggests that it is the body fat distribution, rather than body fat mass or body weight, that is related to early pubertal development. Underweight females (15\% below ideal body weight) have been reported to have a higher incidence of oligomenorrhea (menses 35 days or more apart) and amenorrhea and to have a higher prevalence of ovu- 
latory infertility than normal weight females (Green, Weiss, \& Daling, 1986). Underweight women also give birth to infants who are small and growth delayed, and such infants often have permanently impaired intellectual and physical development (Supy, Steer, McCusker, Steele, \& Jacobs, 1988).

Menstrual dysfunction and ovulatory infertility also occur more often in females who are $20 \%$ above ideal body weight (Green et al., 1986). Morbid obesity in females with high WHR has been shown to increase the degree of androgenicity (increased percentage of free testosterone) and associated menstrual and ovulatory problems (Kirschner \& Samojilik, 1991). Thus, the reproductive success of a woman may be low in spite of a high level of fat deposits if the regional distribution of fat is not appropriate, that is, gynoid.

Finally, the finding that underweight figures were assigned high rankings for youthfulness but not for attractiveness (or other attributes related to reproductive potential) is difficult to reconcile with some evolutionarily based mate selection hypotheses. Youthfulness and health have been proprosed as absolute criteria for female attractiveness (Symons, 1987). Features of physical appearance associated with youth supposedly provide the strongest and most reliable cues for female reproductive potential. The present finding illustrates that the relationship of youthfulness and attractiveness is quite complex. A woman who is judged to be attractive is also found to be youthful; however, youthfulness alone does not make a woman attractive. Apparently, youthfulness is a necessary, but not a sufficient condition, for determination of female physical attractiveness.

\section{Study 3}

This study was conducted to investigate whether older men also find female figures with low WHR attractive. The rationale for this study was to evaluate the adaptive significance of female attractiveness. One of the essential evidences needed to label any trait as adaptive is to demonstrate that the trait is transgenerationally stable (Caro \& Borgerhoff Mulder, 1987). If WHR signals female attractiveness and if attractiveness indeed has adaptive significance, then it should be possible to demonstrate that both younger and older men use WHR to assess female attractiveness. Furthermore, if the ideal of female attractiveness is arbitrary and ever changing, no evidence of transgenerational stability in the meaning of WHR should be found, as older men are more likely to be exposed to different ideals of attractiveness than are younger men.

\section{Method}

Subjects and stimulus materials. White men ages 25-85 were tested. The subjects represented a wide range of education and socioeconomic status: white collar professionals (e.g., lawyers, medical doctors, accountants, professors, air force officers, and computer programmers) as well as blue collar workers (e.g., army recruits representing a vast range of education and work experience). ${ }^{3}$ The final sample $(n=$ 89) represented the following age ranges: $25-34(n=19), 35-44(n=22)$, 45-54 $(n=16), 55-64(n=19), 65-74(n=8)$, and 75-85 $(n=5)$. The same two alternate forms of female figures were used as reported for Study 2.

Procedure. The stimulus figures along with a printed cover story and ranking sheet were given to the subjects to fill out individually and privately. The data sheets were hand delivered to the office or residence of the subject), and after completion they were collected by research assistants.

\section{Results and Discussion}

Rankings of attractiveness and other attributes were strikingly similar for all age groups, and no age trends were discernible for differential rank assignment as a function of age. To ascertain whether relative age affected ranking of various attributes, Spearman rank correlations (rhos) were computed for two age groups: 25 - to 44-year-old subjects and 45- to 85-year-old subjects. The correlations between these two extreme age groups for various attributes were attractiveness-sexiness $=.86$, healthy $=.77$, youthful $=.83$, desire and capability for having children $=.82$. Such highly positive and significant correlations suggest that both age groups ranked figures for various attributes on a similar basis. Similarly, all age groups rated Figure N7 as most attractive and assigned quite similar rankings to various attributes. Table 3 presents mean percentage rankings (mean ranking of 12 subtracted from mean ranking of 1) for Figure $\mathrm{N} 7$ by various age groups. The data in Table 3 clearly show that Figure N7, which was ranked as most attractive by college-age men (Study 2), was similarly rated by various age groups for all of the attributes.

There was also no systematic age effect in ranking for various attributes for three body weight categories. Figure 7 compares composite percentage rankings for various attributes by older subjects (all age groups combined) with rankings assigned by college-age men from Study 2 for three body weight categories.

Whereas both younger and older subjects ranked Figure N7 as most attractive, Figure U7 was ranked attractive by only $5 \%$ of older men, compared with $25 \%$ of younger men. Furthermore, older men reacted to under- and overweight categories and their relationship to health and desire and capability for having children differently: Older men did not associate health with underweight figures, including those with lower WHR. In addition, older men did not assign as low a ranking for desire and capability for having children to high-WHR overweight figures as did the younger men.

In spite of these differences between younger and older male subjects there was consensus across age groups on many inferences. Figure N7 was rated as most attractive, healthy, and as having the highest reproductive potential by both younger and older subjects. A similar linkage between attractiveness-sexiness and desire and capability for having children was not evident for underweight female figures: Men, especially the younger ones, ranked female figures with lower WHR as more attractive and sexy but as less desirable and capable of having children. Likewise, overweight female figures with lower WHR were ranked higher for desire and capability for having children (although not higher than normal figures with low WHR), but both younger and older men assigned them lower rankings for

\footnotetext{
${ }^{3}$ Various organizations (Ammy Reserve Unit, Air Force Officers Club, law and accounting firms, and medical clinics) were contacted. In addition, some questionnaires were filled out by some of Devendra Singh's acquaintances, neighbors, or research assistants and by parents and grandparents of some students.
} 
Table 3

Mean Percentage of Composite Ranking for Various Attributes by Age Group for Normal Weight Figure

\begin{tabular}{|c|c|c|c|c|c|}
\hline \multirow[b]{2}{*}{ Attribute } & \multicolumn{5}{|c|}{ Age groups } \\
\hline & $\begin{array}{c}18-22 \\
(n=106)\end{array}$ & $\begin{array}{c}25-34 \\
(n=19)\end{array}$ & $\begin{array}{c}35-44 \\
(n=22)\end{array}$ & $\begin{array}{c}45-54 \\
(n=16)\end{array}$ & $\begin{array}{c}55+ \\
(n=21)\end{array}$ \\
\hline $\begin{array}{l}\text { Attractive and } \\
\text { sexy }\end{array}$ & 52.3 & 65.0 & 68.2 & 60.5 & 76.2 \\
\hline Healthy & 47.2 & 73.7 & 68.2 & 73.7 & 57.1 \\
\hline Youthful & 26.5 & 10.5 & 18.2 & 26.3 & 28.6 \\
\hline $\begin{array}{l}\text { Desire and } \\
\text { capability } \\
\text { for having } \\
\text { children }\end{array}$ & 31.8 & 31.6 & 29.5 & 31.6 & 30.9 \\
\hline
\end{tabular}

Note. Figure N7, the normal weight figure, had a waist-to-hip ratio of.7.

attractiveness-sexiness or for good health. Taken together, these data demonstrate transgenerational stability in utilization and meaning of WHR and strengthen the contention that female physical attractiveness is adaptive.

\section{General Discussion}

The present findings suggest that body fat and its distribution play a critical role in judgments of female attractiveness, health, youthfulness, and reproductive potential. All of these attributes are associated with a female figure of normal body weight and low WHR. Neither body weight nor WHR alone is associated with female attractiveness. Highly attractive women must have a low WHR; yet deviation from normal body weight, either lower or higher, reduces attractiveness and perceived healthiness. It should be pointed out that attractiveness and health were strongly linked; figures judged to be highly attractive were also perceived as very healthy. It could be, as suggested by Hamilton and Zuk (1982) that good health is the defining feature of attractiveness.

The present study attempted to investigate the role of body fat distribution as reflected by WHR in attractiveness while keeping other bodily features constant. The examination of the role of this single feature in attractiveness was conducted because (a) WHR is the only known feature that has direct bearing on proximate mechanisms regulating health and reproductive capability in humans, and (b) the waist and buttocks (which are included in the measurement of hips) are uniquely human features. None of the great apes (orangutan, chimpanzee, and gorilla) have waist and buttocks (Schultz, 1969). ${ }^{4}$ Thus, WHR might have some unique functional significance in humans. The present findings demonstrate that men have a mechanism to detect this signal and use it in making judgments of female attractiveness. The next logical step would be to investigate the conditions or factors that lead body fat distribution to become a sexually dimorphic feature in humans.

\section{Adaptive Significance of WHR}

The differential energy requirement for reproductive success is one of the most striking differences between the genders.
The female provides energy for the development of the fetus and continues to provide a great amount of nourishment (milk) to a child after birth. This difference in reproductive energetics between males and females would lead to selective pressure in itself and explain the sexual dimorphism in amount of total body fat. Although both males and females need stored fat to cope with short-term food shortage, a female's success in survival and reproduction would require not only a greater amount of stored fat than would a male's but also that a significant portion of the fat be available preferentially during pregnancy and lactation. Indeed, this seems to be the case. The fat deposit from the gluteofemoral region is almost exclusively used during late pregnancy and lactation (Björntorp, 1987, 1991a; RebuffeScrive, 1987a). Thus, the selection pressures can explain why the onset and maintenance of menstrual cycles are associated with attainment of critical fat deposits (Frisch, 1990; Frisch \& McCarthur, 1974). Apparently, the reproductive sequence in a woman cannot be initiated until she has developed an energy buffer to cope with potential future food shortage, thereby ensuring her reproductive success.

Men do not need as much fat storage as women for their reproductive success. Reproductive success of men depends, in part, on muscular strength, which enables them to successfully hunt, defend territory, and combat for acquisition and protection of their mate and offspring. Such differential demands would have produced sexually dimorphic morphological changes and resultant distribution of body fat.

It would follow that males who sought and were successful in mating with females with gynoidal fat distribution would leave more progeny than males who indiscriminately mated with females. The greater reproductive success of such females would maximize their contribution to the gene pool of future generations. Over time, males would favor females with gynoidal fat distribution and find such females more attractive and desirable. Conceived in this manner, gynoidal fat and its measure, WHR, become attractive because of their linkage with the concealed reproductive value of the female.

Historically and cross-culturally, gynoidal fat has been associated with female fertility. For example, Pontius (1987) reported that all stone-age female figures from ancient Europe representing fertility goddesses have gynoidal fat more in common than any other bodily feature. On the basis of his cross-cultural studies Eibl-Eibesfeldt (1989) has found that men in some present-day cultures respond to women who correspond to stone-age idols, although he stressed that such idols do not depict the idealized sexual partner but rather "the mature woman and successful mother, not because such idols were considered to be particularly attractive sexually but because they symbolize the fertile mother" (p. 253). Our findings, however, suggest that at least American young and old men find nonobese women with gynoid body fat distribution both sexually attractive and fertile.

An additional advantage of gynoidal fat in women is that it

\footnotetext{
${ }^{4}$ The buttocks evolved because of the rotation of the sacrum and pelvis and development of the gluteus maximus muscle for bipedal posture. The waist is created by the short ilium, increased development of the lumbar vertebrae, and the lumbar curvature of the spine, emphasized by subcutaneous fat on the gluteal fascia (Schultz, 1969).
} 

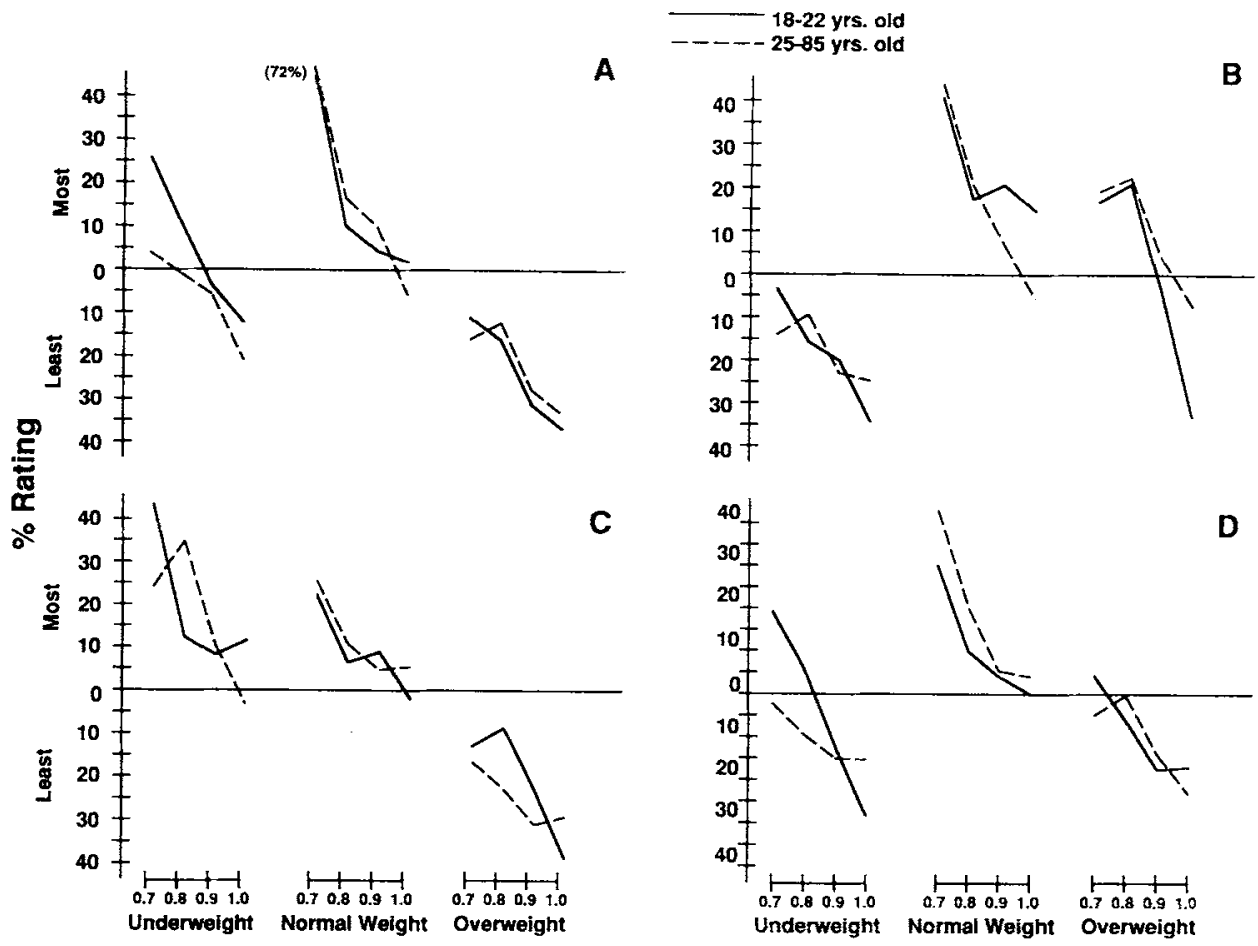

Figure 7. Comparison of average percentage composite ranking for various attributes as a function of body weight categories and waist-to-hip ratio by older subjects and college-age subjects (data from Study 2). ( $\mathrm{A}=$ attractive and sexy, $\mathrm{B}=$ desire and capability for having children, $\mathrm{C}=$ youthful looking, and $\mathrm{D}=$ healthy; yrs. $=$ years)

not only accurately signals the reproductive potential of the woman, but it is also orientation independent: It remains constant whether viewed from front, behind, or side. As a matter of fact, the degree of femininity can be easily and accurately assessed by viewing the back body of a woman (Bayer \& Bayley, 1959). Although some investigators (cf. Gallup, 1986) have proposed that breasts signal reproductive value of a woman, whereas others have suggested that the breast evolved to mimic buttocks (D. Morris, 1967), breasts do not always accurately reflect the reproductive capability of a woman. For example, true hermaphrodites and women suffering from bilateral adrenal tumors have fully formed and developed breasts but are infertile (Jaffe, 1986). Interestingly enough, however, such women also have malelike WHR. WHR appears to be the only feature that accurately signals the reproductive capability of a woman. It could be this factor that magnifies the sexual attractiveness of a woman who has shapely breasts and broad hips set against a narrow waist, the hourglass figure. In the same vein, the bodily feature that is most altered by pregnancy in a woman is the waist. Thus, a high WHR may mimic pregnancy and thereby make the woman less sexually attractive. This could have been an additional reason for our subjects' assigning low attractiveness ratings to all female figures, normal, underweight, or overweight, who had high WHR.

\section{Criteria for Female Mate Selection: A Hypothesis}

Obviously, men do not select women for mating solely on the basis of WHR. However, WHR may be involved in initial stages of mate selection such as the decision to seek and initiate contact with the woman. ${ }^{5}$ WHR could act as a wide first-pass filter, which would automatically exclude those women who are unhealthy or have low reproductive capability. A man may not even be aware of this initial selectivity, except in the case of grossly high WHR such as associated with morbid obesity and pregnancy. If the situation is appropriate, the man may make contact with a potential mate, and in that event a second and much narrower filter may become operative. At this level certain other bodily features and facial attributes can be processed.

Human societies that face frequent food shortage or must depend primarily on hard labor to acquire and store food may find strong legs and arms or overall plumpness of the body more attractive. Other societies may not find such features attractive because of different environmental conditions and constraints in which their society evolved. The degree of affluence of a society or of an ethnic group within the society may, to

\footnotetext{
'The other features such as good muscle tone, skin complexion, lustrous hair, and other behavioral indicators of youth (Buss, 1989; Symons, 1979) may also be involved in this initial stage. However unlike WHR, such features are not directly related to the reproductive endocrinologic status of a woman. Features of youthfulness could be providing cues for a different component of reproductive potential than that provided by WHR. Thus, it could be that, whereas WHR is indicative of current reproductive status, the features associated with youth convey information about expected future reproduction.
} 
a large extent, determine the prevalence and admiration of fatness. A majority of studies investigating the relationship between socioeconomic status (SES) and obesity have found a positive relationship between SES and obesity in both sexes in developing societies, whereas a negative relationship between SES and obesity is found in developed societies (Sobal \& Stunkard, 1989). Obesity is more prevalent in Black Americans than in White Americans, and it has been reported that fatness in Black Americans is associated with a positive stereotype. Black American men have been found less likely to refuse to date an overweight woman and, unlike White Americans, consider an overweight woman to be attractive and sexy (Harris et al., 1991). If the present hypothesis is valid, however, Black American men should find overweight women with low WHRs to be relatively more attractive. No such data are yet available.

At this second level, cultural forces can freely operate as long as alteration or modification in bodily features, such as bound feet, compressed forehead, embossed facial skin, or perforated lips, do not obscure or contradict the signal associated with reproductive success. Culturally defined alteration of body and face by temporary (jewelry) or permanent (embossed skin or tattoo) ornamentation probably plays an important role in group identity and status and prestige in the group, and such ornamentation may enhance the desirability of the woman to men of that society.

At this level, facial features also play a critical role in determining overall attractiveness. There are certain features that make faces attractive to adults (Cunningham, 1986), and young children also prefer those adult faces that are rated attractive by adults (Langlois et al., 1987). Some facial features can convey signals that evoke a caring response, inhibit aggression, and thus may be more engaging or attractive. The face is an expressive organ that can communicate a person's inner feelings, mood, and intentions. Facial expression in emotional display are culture free and can effectively and accurately convey to a member of the opposite gender sexual and romantic intentions (Eibl-Eibesfeldt, 1989). For sexual pairing, facial gestures that convey interest and willingness to another person may lead to initial courtship and eventual mating.

It would seem that, if male-female pairing is to lead to a long-term relationship such as marriage, a final and most restrictive filter relating to personality factors becomes operative. This final filter in all probability would be the most culturally biased. At this level similarity of attitudes held, religious affiliation, sense of humor, compatibility, and a host of other culturally conditioned variables come into play in selecting the mate by both men and women. If such a hierarchical filter system is indeed operative, it can integrate and explain the interplay of biological and cultural factors in determining the mate value of a person. Such a biocultural interaction has to exist if selection pressure has indeed been operative in shaping the mechanisms involved in mate selection.

If there is any merit to the present proposal, then the standardized cross-cultural studies should find diverse notions of what constitutes attractiveness in bodily (stature and breast size) and facial features (i.e., complexion, shape and color of teeth, shape of lips, etc.) and associated personality factors (shy or aggressive, sense of humor, or submissiveness) only. WHR, the first filter, should be culturally invariant in its significance and its relationship to female attractiveness. The fact that WHR conveys such significant information about the mate value of a woman suggests that men in all societies should favor women with a lower WHR over women with a higher WHR for mate selection or at least find such women sexually attractive. Crosscultural studies would be needed to test the validity of these suggestions.

\section{References}

Ashwell, M., Cole, T. J., \& Dixon, A. K. (1985). Obesity: New insight into the anthropometric classification of fat distribution shown by computed tomography. British Medical Journal, 290, 1692-1694.

Barbieri, R. L. (1990). The role of adipose tissue and hyperinsulinemia in the development of hyperandrogenism in women. In R. E. Frisch (Ed), Adipose tissue and reproduction (pp. 42-57). Basel, Switzerland: Karger.

Bayer, L. M., \& Bayley, N. (1959). Growth diagnosis. Chicago: University of Chicago Press.

Bivans, A. M. (1991). Miss America: In pursuit of the crown. New York: Mastermedia.

Björntorp, P. (1987). Fat cell distribution and metabolism. In R. J. Wurtman \& J. J. Wurtman (Eds.), Human obesity (pp. 66-72). New York: New York Academy of Sciences.

Björntorp, P. (1988). The associations between obesity, adipose tissue distribution and disease. Acta Medica Scandinavica, (Suppl.), 723, 121-134.

Björntorp, P. (199 1 a). Adipose tissue distribution and function. International Journal of Obesity, 15, 67-81.

Björntorp, P. (1991b). Visceral fat accumulation: The missing link between psychosocial factors and cardiovascular disease? Journal of Internal Medicine, 230, 195-201.

Buss, D. M. (1987). Sex differences in human mate selection criteria: An evolutionary perspective. In C. Crawford, M. Smith, \& D. Krebs (Eds.), Sociobiology and psychology: Ideas, issues and application (pp. 335-351). Hillsdale, NJ: Erlbaum.

Buss, D. M. (1989). Sex differences in human mate preferences: Evolutionary hypotheses tested in 37 cultures. Behavioral and Brain Sciences, 12, 1-49.

Caro, T. M., \& Borgerhoff Mulder, M. (1987). The problem of adaptation in the study of human behavior. Ethology \& Sociobiology, 8 , 61-72.

Cronk, C. E., \& Roache, A. F. (1982). Race- and sex-specific reference data for triceps and subscapular skinfolds and weight/stature. American Journal of Clinical Nutrition, 35, 347-354.

Cunningham, M. R. (1986). Measuring the physical in physical attractiveness: Quasi-experiments on the sociobiology of female facial beauty. Journal of Personality and Social Psychology, 50, 925-935.

Darwin, C. (1871). The descent of man and selection in relation to sex (1874 ed.). London: John Murray.

Davison, M. L. (1983). Multidimensional scaling. New York: Wiley.

Davison, M. L., \& Skay, C. L. (1991). Multidimensional scaling and factor models of test and item responses. Psychological Bulletin, 110 , 551-556.

DeRidder, C. M., Bruning, P. F., Zonderland, M. L., Thijssen, J. H. H., Bonfrer, J. M. G., Blankenstein, M. A., Huisveld, I. A., \& Erich, W. B. M. (1990). Body fat mass, body fat distribution and plasma hor mones in early puberty in females. Journal of Clinical Endocrinology and Metabolism, 70, 888-893.

Després, J. P., Prudhomme, D., Pouliot, M., Tremblay, A., \& Bouchard, C. (1991). Estimation of deep abdominal adipose-tissue accumulation from simple anthropometric measurements in men. American Journal of Clinical Nutrition, 54, 471-477.

Eibl-Eibesfeldt, I. (1989). Human ethology. Chicago: Aldine. 
Evans, D. J., Hoffman, R. G., Kalkhoff, R. K., \& Kissebah, A. H. (1983). Relationship of androgenic activity to body fat topography, fat cell morphology and metabolic aberrations in premenopausal women. Journal of Clinical Endocrinology and Metabolism, 57, 304310.

Fallon, A. E., \& Rozin, P. (1985). Sex differences in perceptions of desirable body shape. Journal of Abnormal Psychology, 94, 102-105.

Feingold, A. (1990). Gender differences in effects of physical at tractiveness on romantic attraction: A comparison across five research paradigms. Journal of Personality and Social Psychology, 59, 981-993.

Ford, C. S., \& Beach, F. A. (1951). Patterns of sexual behavior. New York: Harper

Frisch, R. E. (1990). Body fat, menarche, fitness and fertility. In R. E. Frisch (Ed.), Adipose tissue and reproduction (pp. 1-26). Basel, Switzerland: Karger.

Frisch, R. E., \& McCarthur, J. W. (1974). Menstrual cycles: Fatness as a determinant of minimum weight for height necessary for their maintenance or onset. Science, $185,548-556$.

Furnham, A., Hester, C., \& Weir, C. (1990). Sex differences in the preferences for specific female body shape. Sex Roles, 22, 743-754.

Gallup, G. G. (1986). Unique features of human sexuality in the context of evolution. In D. Byrne \& K. Kelley (Eds.), Alternative approaches to the study of sexual behavior (pp. 13-41). Hillsdale, NJ: Erlbaum.

Garner, D. M., Garfinkel, P. E., Schwartz, D., \& Thompson, M. (1980). Cultural expectations of thinness in women. Psychological Reports, 47, 183-191.

Green, B. B., Weiss, J. S., \& Daling, J. R. (1986). Risk for ovulatory infertility in relation to body weight. Fertility and Sterility, 50, 721726.

Hamilton, W. D., \& Zuk, M. (1982). Heritable true fitness and bright birds: A role for parasites? Science, 218, 384-387.

Harris, M. B., Walters, L. C., \& Waschull, S. (1991). Gender and ethnic differences in obesity-related behaviors and attitudes in a college sample. Journal of Applied Social Psychology, 21, 1545-1577.

Hartz, A. J., Rupley, D. C., \& Rimm, A. A. (1984). The association of girth measurement with disease in 32,856 women. American Journal of Epidemiology, 119, 71-80.

Jaffe, R. B. (1986). Disorders of sexual development. In S. S. C. Yen \& R. B. Jaffe (Eds.), Reproductive endocrinology (2nd ed., pp. 283-312). Philadelphia: W. B. Saunders.

Jones, P. R. M., Hunt, M. J., Brown, T. P., \& Norgan, N. G. (1986). Waist-hip circumference ratio and its relation to age and overweight in British men. Human Nutrition: Clinical Nutrition, 40C, 239-247.

Kaye, S. A., Folsom, A. R., Prineas, R. J., Potter, J. D., \& Gapstur, S. M. (1990). The association of body fat distribution with lifestyle and reproductive factors in a population study of postmenopausal women. International Journal of Obesity, 14, 583-591.

Kenrick, D. T. (1989). Bridging social psychology and sociobiology: The case of sexual attraction. In R. W. Bell \& N. J. Bell (Eds.), Sociobiology and social sciences (pp. 5-23). Lubbock, TX: Texas Tech University Press.

Kirschner, M. A., \& Samojilik, E. (1991). Sex hormone metabolism in upper and lower body obesity. International Journal of Obesity, 15 , 101-108.

Krotkiewski, M., \& Björntorp, P. (1978). The effects of estrogen treatment of carcinoma of the prostate on regional adipocyte size. Journal of Endocrinological Investigation, 1, 365-366.

Kruskal, J. B., \& Wish, M. (1978). Multidimensional scaling. Beverly Hills: Sage.

Langlois, J. H., Roggmen, L. A., Casey, R. J., Ritter, J. M., Rieser-Danner, L. A., \& Jenkins, V. Y. (1987). Infant preferences for attractive faces: Rudiments of a stereotype? Developmental Psychology, 23, 363-369.

Lanska, D. J., Lanska, M. J., Hartz, A. J., \& Rimm, A. A. (1985). Factors influencing anatomical location of fat tissue in 52,953 women. International Journal of Obesity, 9, 29-38.

Lapidus, L., Helgesson, O., Merck, C., \& Björntorp, P. (1988). Adipose tissue distribution and female carcinomas: A 12-year follow-up of participants in the population study of women in Gothenburg, Sweden. International Journal of Obesity, 12, 361-368.

Larsson, B. (1985). Obesity and prospective risk for associated diseases with special reference to the importance of adipose tissue distribution. In J. Vague, P. Björntorp, B. Guy-Grand, M. Rebuffé-Scrive, \& P. Vague (Eds.), Metabolic complications of human obesities (pp. 2129). Amsterdam: Excerpta Medica.

Leibel, R. L., Edens, N. K., \& Fried, S. K. (1989). Physiologic basis for the control of body fat distribution in humans. Annual Reviews of Nutrition, 9, 417-443.

Marti, B., Tuomilehto, J., Saloman, V., Kartovaara, L., Korhonen, H. J., \& Pietinen (1991). Body fat distribution in the Finnish population: Environmental determinants and predictive power for cardiovascular risk factor levels. Journal of Epidemiology and Community Health, 45, 131-137.

Mazur, A. (1986). U.S. trends in feminine beauty and overadaptation. Journal of Sex Research, 22, 281-303.

Mehrens, W. A., \& Lehman, I. J. (1978). Measurement and evaluation in education and psychology (2nd ed.). New York: Holt, Reinhart \& Winston.

Metropolitan Life Insurance Company. (1959). New weight standards for men and women. Statistical Bulletin, 40, 1-4.

Møller, A. P. (1990). Parasites and sexual selection: Current studies of the Hamilton and Zuk hypothesis. Journal of Evolutionary Biology, 3, 319-328.

Morris, A., Cooper, T., \& Cooper, P. J. (1989). The changing shape of female fashion models. International Journal of Eating Disorders, 8 , 593-596.

Morris, D. (1967). The naked ape. London: Jonathan Cape.

Morris, D. (1985). Bodywatching. New York: Crown Publishing.

O'Brien, R., \& Shelton, W. C. (1941). Womens measurements for garment and pattern construction (Miscellaneous Publication No. 454). Washington, DC: U.S. Department of Agriculture.

Pond, C. M. (1981). Storage. In C. R. Townsend \& P. Carlow (Eds.), Physiological ecology (pp. 190-219). Sunderland, MA: Sinauer Associates.

Pontius, A. A. (1987). Obesity types in stone age art: A study in iconodiagnosis. In R. J. Wurtman \& J. J. Wurtman (Eds.), Human obesity (pp. 331-334). New York: New York Academy of Sciences.

Posnick, P. (1991, August). The return of the waist. Vogue, pp. 260-262.

Raison, J., \& Guy-Grand, B. (1985). Body fat distribution in obese hypertensives. In J. Vague, P. Björntorp, B. Guy-Grand, M. RebufféScrive, \& P. Vague (Eds.), Metabolic complications of human obesities (pp. 67-75). Amsterdam: Excerpta Medica.

Rebuffé-Scrive, M. (1987a). Regional adipose tissue metabolism in men and in women during menstrual cycle, pregnancy, lactation and menopause. International Journal of Obesity, 11, 347-355.

Rebuffé-Scrive, M. (1987b). Regional adipose tissue metabolism in women during and after reproductive life and in men. In E. M. Berry, S. H. Blond heim, H. E. Elihau, \& E. Schafrir (Eds.), Recent advances in obesity research (pp. 82-91). London: John Libbey \& Company.

Rebuffe-Scrive, M. (1988). Metabolic differences in fat deposits. In C. Bouchhard \& F. E. Johnston (Eds.), Fat distribution during growth and later health outcomes (pp. 163-173). New York: Alan R. Liss.

Rebuffé-Scrive, M. (199i). Neuroregulation of adipose tissue: Molecular and hormonal mechanisms. International Journal of Obesity, 15 , 83-86.

Rebuffé-Scrive, M., Cullberg, G., Lundberg, P. A., Lindstedt, G., \& Björntorp, P. (1989). Anthropometric variables and metabolism in polycystic ovarian disease. Hormone Metabolic Research, 21, 391397. 
Rozin, P., \& Fallon, A. (1988). Body image, attitudes to weight, and misperceptions of figure preferences of the opposite sex: A comparison of men and women in two generations. Journal of Abnormal Psychology, 97, 342-345.

Rudofsky, B. (1974). The unfashionable human body. New York: Anchor Books.

Schapira, D. V., Kumar, N. B., Lyman, G. H., Cavanagh, D., Roberts, J. W. S., \& LaPolla, J. (1991). Upper-body fat distribution and endometrial cancer risk. Journal of American Medical Association, 266, $1808-1811$.

Schiffman, S. S., Reynolds, M. L., \& Young, F. W. (1981). Introduction to multidimensional scaling. San Diego, CA: Academic Press.

Schultz, A. H. (1969). The life of primates. New York: University Books.

Shorter, E. (1982). A history of woman's body. New York: Basic Books.

Silverstein, B., Perdue, L., Peterson, B., \& Kelly, E. (1986). The role of the mass media in promoting a thin standard of bodily attractiveness for women. Sex Roles, 14, 519-532.

Sobal, J., \& Stunkard, A. J. (1989). Socioeconomic status and obesity: A review of the literature. Psychological Bulletin, 105, 260-275.

Supy, Z. M. V. D., Steer, P. J., McCusker, M., Steele, S. J., \& Jacobs, H. S. (1988). Outcome of pregnancy in underweight women after spontaneous and induced ovulation. British Medical Journal, 296, 962 965.
Symons, D. (1979). The evolution of human sexuality. Oxford, England: Oxford University Press.

Symons, D. (1987). An evolutionary approach: Can Darwin's view of life shed light on human sexuality? In J. H. Geer \& W. T. O'Donohue (Eds.), Theories of human sexuality (pp.91-125). New York: Plenum Press.

Tonkelaar, I., Seidell, J. C., van Noord, P. A. H., Baander-van Halewijn, E. A., \& Ouwehand, I. J. (1990). Fat distribution in relation to age, degree of obesity, smoking habits, parity and estrogen use: A crosssectional study in 11,825 Dutch women participating in the DOMProject. International Journal of Obesity, 14, 753-761.

Townsend, J. M. (1989). Mate selection criteria: A pilot study. Ethology and Sociobiology, 10, 241-253.

Vague, J. (1956). The degree of masculine differentiation of obesities: A factor determining predisposition to diabetes, atherosclerosis, gout and uric calculous disease. American Journal of Clinical Nutrition, 4, 20-34.

Wilson, G., \& Nias, D. (1976). Love's mysteries. New York: Fontana/ Collins.

Received May 27, 1992

Revision received January 18, 1993

Accepted January 25, 1993

\section{American Psychological Association SUBSCRIPTION ClaIMS INFORMATION}

Today's Date:

We provide this form to assist members, institutions, and nonmember individuals with any subscription problems. With the appropriate information we can begin a resolution. If you use the services of an agent, please do NOT duplicate claims through them and directly to us. PLEASE PRINT CLEARLY AND IN INK IF POSSIBLE.

PRINT FULI NAME OR KEY NAME OF RNSTTUTION

ADDRESS

CITY STATECOUNTRY ZP

YOUR NAME AND PHONE NUMBER

TTLE

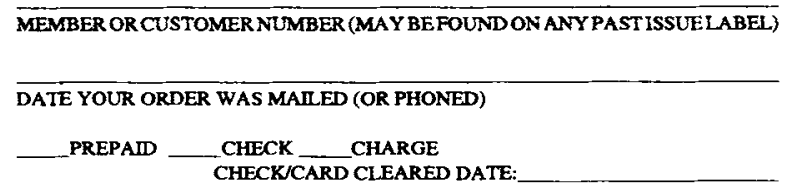

(If possible, send a copy, front and back, of your cancelled check to help us in our reseanch of your claim.)

ISSUES: __ MISSING _ DAMAGED

NUMBER OR MONTH

Thank you. Once a claim is received and resolved, delivery of replacement issues routinely takes $4-6$ weeks.

(TO BE FILLED OUT BY APA STAFF)

DATE RECEIVED:

ACTION TAKEN:

STAFF NAME:
DATE OF ACTION:

INV. NO. \& DATE:

LABEL NO. \& DATE:

Send this form to APA Subscription Claims, 750 First Street, NE, Washington, DC 20002-4242

PLEASE DO NOT REMOVE. A PHOTOCOPY MAY BE USED. 